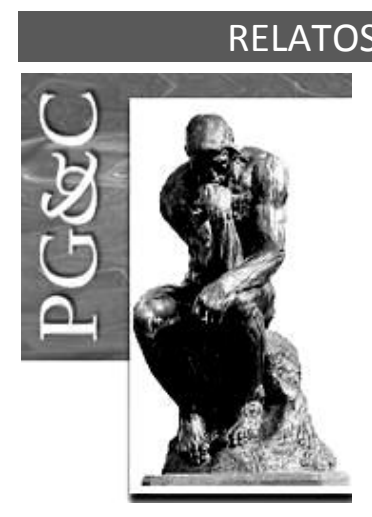

\title{
EXPERIÊNCIA DIDÁTICA NA APLICABILIDADE E ESTRUTURAÇÃO DA APRENDIZAGEM BASEADA EM PROBLEMAS (ABP): PERCEPÇÕES DOS ALUNOS DO CURSO DE ADMINISTRAÇÃO E RECOMENDAÇÕES PARA IMPLEMENTAÇÃO
}

\author{
André Luiz Barbosa da Silva \\ Doutor em Administração pela Fundação Getúlio Vargas de São Paulo, \\ Brasil. Professor do Centro Universitário São Camilo, Brasil. \\ E-mail: andreluizbsilva@gmail.com
}

\section{Resumo}

A efetiva implementação da aprendizagem baseada em problemas ( $A B P$ ) no curso de administração necessita de maior atenção, haja vista a natureza do trabalho dos futuros administradores. Assim, o objetivo central da pesquisa é demostrar como estruturar e aplicar o método ABP no curso de Administração. Por meio da abordagem qualitativa busca investigar as experiências na aplicação e implementação do ABP no ensino de administração. Para este fim o método ABP foi implementando na disciplina de planejamento de marketing oferecida no curso de graduação em administração. Os dados foram coletados por meio de observação participante das aulas e notas de pesquisa, além de entrevistas não estruturadas com discentes após a aplicação do método afim de captar as percepções dos alunos. Os dados foram coletados a cada finalização das etapas definidas da problematização, viabilizando a captação das principais dificuldades, oportunidades de melhoria e finalização do projeto ABP. Os resultados demostram a sua relevância da $A B P$ e, em contrapartida, conclui-se a que os docentes carecem de sugestões na forma de implementar o ABP. Assim, a pesquisa apresenta sete recomendações para aplicação desse método de aprendizagem.

Palavras-chave: Aprendizagem baseada em problemas. Implementação ABP. Perspectiva do docente.

\section{DIDACTIC EXPERIENCE ON THE APPLICABILITY AND STRUCTURING OF PROBLEM-BASED LEARNING (PBL): \\ PERCEPTIONS OF STUDENTS OF THE ADMINISTRATION COURSE AND RECOMMENDATIONS FOR IMPLEMENTATION}

\begin{abstract}
The implementation of a problem-based learning course (PBL) does not have a course of administration of greater attention, because it has the nature of the work of future administrators. Thus, the central research is to demonstrate how to structure and apply the PBL method in the Administration course. Through the qualitative approach, it sought to investigate the experiences in the application and implementation of PBL in the teaching of administration. To the end of the implementation was implementing the development program marketing based on graduate course. The data were collected through participant observation of the classes and research notes made by the teacher, besides having been carried out with students after the application of the perception method as students' perceptions. The data were collected at each stage of completion of the problem, enabling the capture of the main difficulties, opportunities for improvement and finalization of the PBL project. The results of the comparison are relevant and, on the other hand, concluded with the teachers evaluating applications for implementation of the PBL. Thus, a research presents seven recommendations for the application of this method of learning.
\end{abstract}

Keywords: Problem-based learning. PBL implementation. Professor perspective.

Perspectivas em Gestão \& Conhecimento, João Pessoa, v. 8, n. 2, p. 179-193 maio./ago. 2018. DOI: http://dx.doi.org/10.21714/2236-417X2018v8n2p179

http://periodicos.ufpb.br/ojs2/index.php/pgc. ISSN: 2236-417X. Publicação sob Licença (cc) EY-NC-ND 


\section{INTRODUÇÃO}

O ambiente educacional percorre uma trajetória de mudanças no processo de ensino-aprendizagem em decorrências das diversas variáveis mercadológicas e precisam acompanhar essa evolução. Um importante desafio para o ensino superior é o desenvolvimento e implementação de práticas de ensino que fomentarão nos alunos a habilidade de aplicar o conhecimento eficientemente (DOCHY et al., 2003) e algumas estratégias educacionais não conseguem atender este pré-requisito. As universidades precisam atentar-se para o desenvolvimento de novas práticas educacionais e que estimule o processo de aprendizagem. Neste sentido, as universidades precisam criar maior aproximação com a realidade e aumentar o significado para os alunos e apresentar sistemas de avaliação que verifiquem de fato as competências dos alunos com um instrumento baseado na vida real, isto é, problemas reais com base em avaliação congruente com a aprendizagem (BAXTER; SHAVELSON, 1994; DOCHY et al., 2003).

Para isso, professores e instituições de ensino devem proporcionar e criar este ambiente que seja capaz de incorporar essa visão multidisciplinar. Um das formas de inovar o processo de aprendizagem é a aplicação do método aprendizagem baseada em problemas $(A B P)$. Esta abordagem tem sido amplamente adotada em diversos campos e contextos educacionais para promover o pensamento crítico e a solução de problemas em situações de aprendizagem autêntica (YEW; GOH, 2016). O ABP apresenta um ensino orientado para o discente e possui como foco a aprendizagem construtiva, contextual e colaborativa (HUNG; JONASSEN; LIU, 2008; SCHMIDT et al., 2009). Essa abordagem chama atenção dos pesquisadores sobre $A B P$ em diversas frentes do conhecimento. Pesquisas avançam no aprofundamento sobre o papel do professor no processo ABP (ASSEN et al., 2016; GOH, 2014; ROTGANS; SCHMIDT, 2011; WIJNIA et al., 2016), a sua efetividade e aplicações (ALBANESE; MITCHELL, 1993; JONES et al., 2010) e a influência no desenvolvimento dos estudantes (DUNLAP, 2005; ELCIN et al., 2006; JONES et al., 2010; TAN; VAN DER MOLEN; SCHMIDT, 2016). Além de abordarem a percepção dos alunos sobre o método (AZER, 2009).

No entanto, alguns pesquisadores tem apontado sobre a relevância sobre como estruturar e avaliar o ABP. Normalmente, observa-se que os esforços de pesquisa anteriores, incluindo as obras mencionadas anteriormente, parecem debater os dois fins do processo de instrução - a concepção teórica e os resultados de aprendizagem dos alunos - sem discutir os processos, que é a implementação do ABP (HUNG, 2011, p. 530). Para Carriger (2015) a avaliação da aprendizagem baseada em problemas deve focar mais diretamente na aplicação do conhecimento e na resolução de problemas, em vez da aquisição de conhecimento. 0 docente deve avaliar as motivações e discussões geradas pelo método em face aos métodos tradicionais de aula. Mas os docentes encontram dificuldades no processos de estruturar a aplicação e suas formas de avaliação.

Desta forma, emerge o principal objetivo desta pesquisa em demostrar como estruturar e aplicar o método ABP em uma disciplina do curso de Administração como estratégia de metodologia ativa do sexto semestre de 2016. Este caso de ensino está dividido nesta introdução, posteriormente, referencial teórico sobre ABP. Em seguida são apresentados os procedimentos metodológicos e a estruturação do ABP como metodologia ativa na disciplina de planejamento de marketing. Por fim as conclusões sobre as dificuldades e formas de replicação para outras instituições.

Perspectivas em Gestão \& Conhecimento, João Pessoa, v. 8, n. 2, p. 179-193, maio/ago. 2018. 


\section{ABORDAGEM DA APRENDIZAGEM BASEADA EM PROBLEMAS}

A aprendizagem baseada em problemas (ABP) tem a sua origem entre 1950 e 1960 e foi influenciado pela insatisfação com a área de educação médica no Canadá (DOCHY et al., 2003), estendendo-se, posteriormente, para a engenharia, direito, biologia e negócios (ASSEN et al., 2016; AZER, 2009; HUNG; JONASSEN; LIU, 2008; SCHMIDT et al., 2009). No entanto, apesar da sua relevância, o conceito de ABP pode apresentar diversos caminhos. Pode ser definida, por exemplo, em razão de sua abordagem pedagógica ativa baseada em problematizações (HUNG, 2011; YEW; GOH, 2016), ou na proposta de aprendizagem colaborativa (SMITH; HOERSCH; GORDON, 1995; WIJNIA et al., 2016).

Mas a aprendizagem baseada em problemas propõe aos alunos casos simulados ou reais para, inicialmente, serem discutidos de forma teórica e, posteriormente, apresentadas soluções práticas como propostas pedagógicas que permitam aos alunos e professores realizar investigações de caráter básico, socializar conhecimentos, desenvolver competências e atitudes que lhes permitam analisar e discutir criticamente a ciência e suas soluções para os problemas presentes no ambiente (BAZANINI; SANTANA, 2015). Tal prática busca a valorização do docente na efetividade do método (GOH, 2014) e (HUNG, 2011) em razão das habilidades voltadas à resolução de situações-problemas (ALBANESE; MITCHELL, 1993; SMITH; HOERSCH; GORDON, 1995).

Nesse contexto, vê-se que o professor deve assumir o papel de facilitador no processo da implementação do ABP ao propor um problema real e pertinente, reforçando a necessidade do discente colocar em prática as suas competências seguidas de propostas de soluções. Compete ao docente a tarefa de pesquisar, integrar teoria/prática e aplicar conhecimentos e habilidades que possibilitam o desenvolvimento de soluções viáveis para um problema definido (SAVERY, 2006). É preciso ter em mente que problemas mal estruturados trazem objetivos vagamente definidos, vários elementos problemáticos desconhecidos, múltiplas soluções plausíveis e ambiguidade sobre os conceitos ou princípios necessários à resolução (JONASSEN, 1997). Trata-se de uma abordagem baseada na reflexão e ampliação da criticidade. Diante disso, o professor precisa entender que o ABP possui uma abordagem centrada no aluno, o que requer a necessidade de assumir o papel de mediador, diretivo e transmissor do conhecimento ao dar exemplos, explicar as relações e fazer distinções entre questões principais e secundárias (ASSEN et al., 2016). Nesse contexto, a metodologia ABP apresenta seis características segundo (DOCHY et al., 2003 apud BARROWS, 1996), a serem implementadas pelo docente:

1. Primeira: a aprendizagem precisa ser centrada no aluno.

2. Segunda: a aprendizagem envolve pequenos grupos de alunos orientados pelo tutor.

3. Terceira: o tutor posiciona-se como facilitador ou guia.

4. Quarta: os problemas são autênticos e entrelaçados à sequência de aprendizagem.

5. Quinta: os problemas encontrados são usados como uma ferramenta para alcançar os conhecimentos e as habilidades de resolução.

6. Sexta: informações novas requerem uma aprendizagem autodirigida.

Cabe ao professor colocar em prática todas essas características apresentando sempre um problema real e representativo, para que seja possível potencializar o interesse do aluno, que identificará os problemas centrais, definirá parâmetros que caminhem para a solução, o que o estimulará a participar da aprendizagem de forma autodirigida (CARRIGER, 2015), para isso, a definição do problema deve ser clara, autêntica e capaz de instigar a pesquisa contínua,

Perspectivas em Gestão \& Conhecimento, João Pessoa, v. 8, n. 2, p. 179-193, maio/ago. 2018. 
pois só assim será possível considerar o conhecimento prévio do aluno e quais lacunas precisam de atenção para avançarem no conhecimento (PETERSON, 2004; SMITH; HOERSCH; GORDON, 1995). O alinhamento da metodologia e prática, pesquisa e ensino, ABP prevê o domínio de princípios e conceitos voltados para a habilidade de selecionar e enfrentar questões, além da sala de aula (BUFREM; SAKAKIMA, 2003). De forma objetiva, o ABP pode preencher a lacuna da teoria e prática na área de gestão empresarial, uma vez que esta área exige do aluno a capacidade de analisar, buscar informações, desenhar cenários e estruturar as suas decisões, o que justifica a importância de estruturar casos de ABP em cursos de administração visando potencializar a aprendizagem dos alunos.

No entanto, O ABP não pode ser considerado apenas uma técnica para resolver problemas e deve-se evitar esta restrição. Masetto (2004) ressalta que o ABP tem metas educacionais mais amplas. Barrows (1996) reforça o ABP ainda que inter-relacionada com processos eficazes de solução de problemas, teria como objetivos principais a aprendizagem de uma base de conhecimentos integrada e estruturada em torno de problemas reais e o desenvolvimento de habilidades de aprendizagem autônoma e de trabalho em equipe, tal como ocorre em situações práticas. Segundo os autores Hadgraft e Holecek (1995) o ABP é uma alternativa válida aos métodos expositivos, pois contemplaria os seguintes objetivos educacionais:

- Aprendizagem ativa, por meio da colocação de perguntas e buscas de respostas;

- Aprendizagem integrada, por intermédio da colocação de problemas para cuja solução é necessário o conhecimento de várias sub-áreas;

- Aprendizagem cumulativa, mediante a colocação de problemas gradualmente mais complexos até atingir aqueles geralmente enfrentados por profissionais iniciantes;

- Aprendizagem para a compreensão, ao invés de para a retenção de informações, mediante a alocação de tempo para a reflexão, feedback frequente e oportunidades para praticar o que foi aprendido

Segundo os autores, a aplicação do ABP possibilita ao discentes maior adaptabilidade as mudanças, capacidade de resolver problemas cotidianos, aumento da criatividade, adoção de uma abordagem mais sistêmica e desenvolvimento de trabalho em equipe. No entanto, mesmo com ênfase no discente, este deve assumir o compromisso com aprendizagem independentemente do método de ensino adotado, já que nada nem ninguém pode forçá-los a aprender se eles mesmos não se empenharem no processo de aprendizagem (TARDIF, 2002), é fundamental nesta abordagem que a responsabilidade pela aprendizagem lhes seja explicitamente delegada. Ou seja, assumir responsabilidade pela própria aprendizagem em um ambiente educacional ABP significa que os alunos cumpram as tarefas propostas pelas metodologia definida (WOODS, 2001). POWELL (2000) atribui à ABP a vantagem de motivar o aluno a trabalhar e a aprender a aprender. Para o autor, devido ao trabalho em grupo há mais comunicação entre os alunos e estes estabelecem mais parcerias entre si e, nos anos mais avançados, com o corpo docente. Ademais, neste contexto educacional os alunos demonstram mais iniciativa, descobrindo o que não sabem e procurando o que precisam para trabalhar no projeto, e também aprendem a respeitar mais os prazos estabelecidos pelos colegas e tutores

\section{PROCEDIMENTOS METODOLÓGICOS}

\subsection{Contexto}

Perspectivas em Gestão \& Conhecimento, João Pessoa, v. 8, n. 2, p. 179-193, maio/ago. 2018. 
O estudo de caso direcionado à aplicação do ABP foi aplicado em uma Instituição de Ensino Superior (IES) de São Paulo, entre o período de agosto e dezembro de 2016, no curso de bacharel em administração, tendo a metodologia ABP aplicada na disciplina de planejamento de marketing, disponibilizada em duas turmas do sexto semestre. Foi estruturado um problema real, com abordagem multidisciplinar, e cada turma percorreu semanalmente duas horas, totalizando 40 horas de pesquisa, análise e solução do problema. A cada aula, os alunos discutiam o problema e partiam para pesquisa de mercado e, posteriormente, para a definição da estratégia de marketing.

Como ponto de partida, estabeleceu-se uma oportunidade real da própria IES, em questão: "Quais estratégias de marketing podem ser desenvolvidas para aumentar a captação de alunos do curso de administração de empresa?". Após a definição do problema, foram esclarecidos eventuais dúvidas relacionadas ao objetivo, no intuito de evitar ambiguidades na pesquisa. Na sequência, analisou-se o problema de forma abrangente, definindo o fluxo de pesquisa e formulação de suas respectivas agendas. A cada etapa percorrida, o professor discutia as informações previamente analisadas com os discentes, para que fosse possível refletir sobre os impactos das suas decisões, construindo, com isso, o conhecimento de forma colaborativa.

\subsection{Design da pesquisa}

Essa pesquisa possui uma abordagem qualitativa descritiva (GIOIA; CORLEY; HAMILTON, 2012; GUBA; LINCOLN, 1994) direcionada a compreender como o docente estruturou de forma participativa o ABP, o que (DENZIN; LINCOLN, 1994; FLICK, 2009) permitiu coletar informações e captar as percepções dos alunos, além das observações do pesquisador. Os dados foram coletados a cada finalização das etapas definidas da problematização, viabilizando a captação das principais dificuldades, oportunidades de melhoria e finalização do projeto $A B P$.

\subsection{Participantes, coleta e análise dos dados}

A pesquisa reuniu o professor e alunos da disciplina de planejamento de marketing totalizando vinte alunos do período noturno. O pesquisador realizou a coleta de notas de pesquisa a cada aula, verificando a evolução dos discentes e possíveis formas de intervenção, além de observar os alunos durante a discussão, coleta de dados e apresentação das informações, para que fosse possível verificar os comportamentos e as técnicas empregadas pelo discente no processo. Foram entrevistados dez alunos, que puderam expor as suas opiniões sobre o desenvolvimento do trabalho e, nesse cenário, o roteiro foi semiestruturado incluindo novas perguntas alinhadas ao posicionamento dos alunos. Cabe ressaltar, que as entrevistas não seguiram a sequência de um protocolo uma vez que novas perguntas foram incluídas sempre que faziam sentido, visando assegurar o fluxo do processo (DENZIN; LINCOLN, 1994), com o intuito de captar as percepções, as motivações e as melhorias no caso do ABP proposto. Ao final foi realizado análise das notas coletadas em cada aula, utilizou-se as anotações realizadas no diário de observação e as entrevistas realizadas. Desta forma, os dados obtidos por meio de diferentes instrumentos de coleta permitiram realizar a triangulação dos dados para aprofundar sobre o processo de implementação, gerando a proposta do fluxo de implantação, conforme Figura 1 apresentada na seção dos resultados.

Perspectivas em Gestão \& Conhecimento, João Pessoa, v. 8, n. 2, p. 179-193, maio/ago. 2018. 


\section{A ESTRUTURAÇÃO E DESENVOLVIMENTO DO CASO ABP NA ADMINISTRAÇÃO}

Com o propósito de instigar os discentes, o professor deve apresentar uma situação real capaz de potencializar o nível de interesse e, em vista disso, foi selecionada a IES onde atua profissionalmente para elaborar uma estratégia de marketing focada no aumento da captação de alunos para o curso de administração de empresas. Após a delimitação do objetivo, os discentes desenvolveram um roteiro de perguntas/questionamentos iniciais, a fim de compreender os fatores endógenos e exógenos passíveis de interferência no processo proposto, o que demonstrou um elevado grau de interesse dos alunos, ampliando o nível de criticidade. Nesta fase, o professor interagiu contribuindo com a formulação e delineamento do problema respondendo questionamentos dos discentes que finalizaram o processo com a construção de um roteiro de pesquisa de campo focado no mercado educacional.

\subsection{Analisando o problema: definindo fluxo do problema}

$O$ roteiro de pesquisa foi apresentado de forma independente e alinhada ao objetivo proposto para que os discentes pudessem trabalhar de forma mais ativa e crítica, o que ensejou uma série de questionamentos mercadológicos face ao posicionamento do curso no mercado educacional, emergindo a necessidade de agruparem conhecimentos de outras disciplinas tais como inteligência de mercado, estratégia, marketing e comportamento do consumidor. Após a conciliação e a aplicação de outras disciplinas no decorrer dos processos, o professor passou a instigar os questionamentos propostos realizando um brainstorm, a fim de evidenciar variáveis possíveis e passíveis de análise e, ao surgirem equívocos, o professor retornava o questionamento a fim de poder fomentar a discussão. Nesse contexto, não houve distanciamento do docente no processo o que acaba por interferir em sua tomada de decisão, muito embora venha favorecer maior interação do discente ao sentir-se mais à vontade.

\subsection{Pesquisa e Análise dos dados}

Após estruturado o quadro, os discentes foram para o laboratório de informática adequando-se à divisão das atividades da pesquisa, ficando cada qual com uma parte para discussão e apresentação de resultados, o que permitiu ao docente a verificação do nível de abstração entre a teoria e prática dos discentes. Cabe ressaltar também que o papel do professor esteve direcionado a questionar os dados pesquisados indicando ao aluno o desenvolvimento de maior autonomia no processo de construção de suas decisões gerenciais, momento crucial para o discente ao ter que apresentar resultados sobre a sua forma de construção e linearidade na tomada de decisão.

Viu-se, portanto, que essa fase permitiu ao grupo criar o cluster de concorrentes por faixa de preço, favorecendo a análise de cada concorrente e seu posicionamento de negócio. Para mensurar esse processo, criaram um check list qualitativo e analisaram trinta e nove sites de empresas concorrentes, roteiro esse também criado por iniciativa dos alunos, para que fosse possível analisar, por exemplo, a facilidade das informações no site, o valor da mensalidade, o excesso de publicidade, se a empresa fornecia bolsa de estudos e seus procedimentos, a quantidade de mestres e doutores, a nota do ENADE, a matriz curricular, a localização, os cursos de extensão, o tipo de infraestrutura, o estágio, carreira, além de intercâmbios.

Perspectivas em Gestão \& Conhecimento, João Pessoa, v. 8, n. 2, p. 179-193, maio/ago. 2018. 


\title{
4.3 Estruturação dos cenários e resultados finais
}

Os alunos analisaram o posicionamento da IES e estruturam uma matriz comparativa, emitindo parecer sobre as possíveis melhorias com base no diferenciais da IES em que estudam, atentando para os valores mercadológicos e os planos de marketing. Foi construída uma apresentação com estratégias específicas à gestão da IES, que posicionou-se de forma positiva perante as estratégias apresentadas ao setor de marketing institucional. Nesta etapa, o professor deve contribuir para articulação e formulação crítica de soluções sem impor os seus ideais e suas propostas, ao contrário, estimulando e mostrando os benefícios e riscos das decisões dos alunos, para que fosse possível potencializar a sua autonomia.

\section{RESULTADOS DA PESQUISA}

Finalizado o processo, o professor estruturou uma discussão sobre as percepções dos discentes que contribuíram de forma livre sobre as possíveis melhorias do método e aplicação em futuras disciplinas, momento de satisfação dos discentes em face do resultado alcançado.

\begin{abstract}
"Foi muito interessante montar um planejamento com um problema real $e$ que sentimos como alunos. Você resolver um problema que vivencia é mais fácil para entender a teoria com pratica." (A1)

"Ver um problema real, problema que não fica só nos livros, nos ajuda muito a fixar conteúdos de outras disciplinas. Você precisa analisar, pensar, ser crítico, retomar o problema, discute com colegas, até chegar em uma proposta viável e real. Diferente quando temos que resolver problemas distantes, com cases que não mostram a nossa realidade, nosso dia-a-dia. Quando fica muito distante fica mais complicado de ver a aplicação da realidade." (A5)
\end{abstract}

Percebe-se que os alunos apresentaram maior engajamento no processo de resolução quando partiram de um problema real dotado de sentido para a sua realidade Savery (2006). Outro aspecto apresentado pelos alunos foi o papel do professor na condução da construção da solução.

\footnotetext{
"Professor ajuda na construção mas não fornecendo as respostas, mas perguntando mais ainda. E ele não fica com comportamento de certo ou errado. Quando eu perguntava ele retornava perguntando o que achava da minha decisão e ficava pensando para responder e ver como minha decisão poderia resolver o caso." (A6)

"O mais legal foi ter essa liberdade de escolher um problema real. Professor permitir esse método nos deixa mais participativo na disciplina. Parece que aprendemos juntos. Outra coisa é que nós que montamos as soluções, a forma de pesquisar. Ele orientava quando desviava muito mas sempre questionamento e não criticando. Isso ajudava bastante." (A7)
}

De acordo com Carriger (2015), à medida que o professor apresenta algo real, a motivação dos alunos é potencializada fortalecendo os parâmetros de decisão, todavia é fundamental para o docente respeitar a literatura (DOCHY et al., 2003), assim como a postura construtiva (HUNG, 2011). À medida que o professor consegue interagir com os alunos, a

Perspectivas em Gestão \& Conhecimento, João Pessoa, v. 8, n. 2, p. 179-193, maio/ago. 2018. 
problemática passa a fazer sentido para todos que contribuíram com a construção Nesse contexto e, sem condição de propor julgamentos, os alunos buscam mais informações e mostram o seu desejo de resolver o problema criando um senso de pertencimento.

"O método permitiu resolver o caso real. Tivemos que buscar informações reais, pesquisar de verdade para criar uma solução real. Isso é muito diferente dos casos que resolvemos durante o curso. Fatos que não sabemos quais impactos poderiam causar. Neste caso foi diferente. Montamos uma decisão para nossa faculdade." (A3)

"Para resolver o problema tivemos que usar conhecimento de outras disciplinas. Temas que já tínhamos vistos retomamos. Consegui ver a aplicação e mais integração. Precisamos ter mais esse tipo de atividades no curso." (A8)

A postura dos alunos mostra que a metodologia ativa proporciona e permite a busca de dados e informações para suprir lacunas no problema, assim como busca novas formas de construir o conhecimento para atingir o objetivo (PETERSON, 2004; SMITH; HOERSCH; GORDON, 1995). Outro fator evidenciado no processo foi o papel do professor e a sua capacidade de tornar-se um mediador da teoria em detrimento à prática. Os alunos reforçam que tal postura contribui para o desenvolvimento e construção do conhecimento dentro do problema proposto.

"O professor com essa atitude ajuda na nossa formação. Ele não julga e não fica distante. Ao contrário, ele sugere e passa as orientações depois que levamos uma solução prévia. Esse era o acordo, discutir o problema a partir de algo que criamos e não o professor já falar direto o que precisamos fazer. Isso gera mais autonomia para nos." (A2)

"O papel do professor neste método é importante. Ele consegue por meio de vários questionamentos mostrar a integração da prática e da teoria. Mas não fala como resolver, ele cria junto, questionando, perguntando, sugerindo reflexões. A cada conversa, discutíamos mais e retornávamos para pensar na nossa conversa. A aula fica muito mais dinâmica e aprendemos mais. $E$ percebi que podemos decidir e ter mais capacidade para solucionar problemas com nossa forma de pensar." (A9)

Nota-se que essa metodologia espera do professor o papel de facilitador e não o centro do conhecimento (DOCHY et al., 2003; HUNG; JONASSEN; LIU, 2008). Desta maneira, o aluno percebe que possui potencialidades e competências a serem desenvolvidas durante $o$ processo, o que reproduz a forma como a abordagem centrada no aluno pode contribuir com a sua formação (BOLHUIS; VOETEN, 2001; CHNG; YEW; SCHMIDT, 2011; GORMAN; HANLON; KING, 1997; HMELO-SILVER; BARROWS, 2006; YEW; GOH, 2016). Desta forma, os resultados da pesquisa indicam que o processo para implementar o ABP podem gerar diversos benefícios para os discentes conforme exposto no Quadro 1.

O processos de aprendizagem permitiu aos discentes promover o processo de aprendizagem de forma mais integrada, atrelada a processos de solução de problemas devido a realidade apresentar vínculo com a realidade do discente. Além disso, pode-se perceber um maior senso de pertencimento dos discentes pois a problemática foi construída em conjunto e não imposta pelo docente. Mas para resolver a problemática os alunos desenvolveram habilidades que contribuíram para construção da solução, como por exemplo, maior responsabilidade e comprometimento com a metodologia proposta. Além disso, este senso de

Perspectivas em Gestão \& Conhecimento, João Pessoa, v. 8, n. 2, p. 179-193, maio/ago. 2018. 
propriedade permitiu ao grupo de alunos um ambiente favorável para exporem as suas ideias de forma mais clara, sem julgamentos do grupo. Ao contrário, a cada exposição os discente apresentam mais argumentações e interligavam conteúdos de outras disciplinas para justificar o seu posicionamento.

Desta forma, discentes apresentam mais confiança e ao mesmo tempo existia uma capacidade de auto-avaliação e reconsiderações eram feitas e novas estruturas de argumentação eram criadas alinhadas com a discussão e senso do grupo. Neste sentido, os discentes promoviam maior cooperação devido ao foco na solução do problema. Mesmo assim, o grupo de discente conseguiram ampliar o seu poder de escuta e criou-se uma estância de respeito nas considerações dos demais colegas, quando exposto. Isso gerou e estimulou o grupo a expressar sem limitações, pois em determinados momentos, os discentes não possuía todas as informações necessárias para resolver o problema e a criatividade foi desenvolvida. Talvez por isso, o senso de respeito e escuta foi mais intensa nas atitudes dos alunos.

Quadro 1 - Dimensões e benefícios do ABP

\begin{tabular}{|c|c|}
\hline Dimensões & Benefícios do ABP \\
\hline $\begin{array}{l}\text { Aprendizagem de } \\
\text { conhecimento }\end{array}$ & $\begin{array}{l}\text { O conhecimento adquirido na disciplina superou a expectativa em face da } \\
\text { metodologia aplicada. } \\
\text { Houve aplicação do conhecimento teórico por meio de pesquisas reais, desta } \\
\text { forma o conteúdo foi melhor assimilado. } \\
\text { Integração entre o problema real e o contexto dos alunos. } \\
\text { Criou-se maior senso de pertencimento entre o aluno e a forma de construção } \\
\text { da aprendizagem. }\end{array}$ \\
\hline $\begin{array}{l}\text { Desenvolvimento } \\
\text { das habilidades }\end{array}$ & $\begin{array}{l}\text { Discentes percebem a sua responsabilidade no entendimento e construção da } \\
\text { solução } \\
\text { Desenvolvimento de senso analítico } \\
\text { Ampliação da visão sistêmica entre as disciplinas estudadas } \\
\text { Autonomia e confiança na forma de expor as ideias } \\
\text { Capacidade de auto-avaliação }\end{array}$ \\
\hline Atitudes & $\begin{array}{l}\text { Melhora na argumentação } \\
\text { Maior cooperação entre os discentes devido ao foco na resolução do problema } \\
\text { apresentado } \\
\text { Ampliou-se a questão da escuta, ou seja, houve mais respeito á opinião dos } \\
\text { outros. } \\
\text { Maior senso de responsabilidade e criatividade para resolver determinadas } \\
\text { etapas devido a ausência de informações do problema } \\
\text { Capacidade de expressão }\end{array}$ \\
\hline
\end{tabular}

Fonte: Elaborado pelo autor

Perspectivas em Gestão \& Conhecimento, João Pessoa, v. 8, n. 2, p. 179-193, maio/ago. 2018. 


\subsection{Discussão dos resultados}

O ABP apresenta como proposta estimular diversos tipos de conhecimento, encorajar visões diferentes sobre o mesmo assunto e promover o trabalho em grupo (TAYLOR; BURGESS, 1999). A metodologia apresenta uma capacidade de integrar os alunos no processo de aprendizagem e busca potencializar a sua autonomia na construção do conhecimento. Este alinhamento entre a teoria e prática, mas fundamentado em um caso real, alinhado a realidade do discente gera efetivamente maior senso de pertencimento, desenvolve competências e atitudes (BAZANINI; SANTANA, 2015).

Pode-se perceber e cabe reforçar que o ABP pode ultrapassar a questão meramente da aplicação do método de solução de problemas, pois quando aplicado apenas com esta finalidade o aluno pode entender como sendo apenas uma questão instrumental. Por isso, o docente deve sempre buscar o alinhamento e a construção da aplicação de simulações aliadas as práticas profissionais do discente com objetivo de instigar a busca de soluções não apenas para problema proposto, mas como reforça Boud e Feletti (1999), os alunos podem se beneficiar de fazer algo valoroso para outras pessoas, supervisionados de forma adequada e orientados de modo a garantir que seja uma experiência significativa. Ou seja, por meio das problemáticas criadas o docente pode ampliar as discussões além da proposta da disciplina, como por exemplo, questões éticas das práticas dos administradores.

Mesmo com os benefícios propostos do ABP cabe ressaltar o papel do docente neste processo de implementação do método. Sabe-se que o docente deve buscar problemas e com senso de pertencimento real ao contexto dos alunos para ampliar o seu interesse na disciplina (CARRIGER, 2015). Além disso, a literatura explora que a seleção do problema deve ser coerente e instigar a pesquisa do aluno de forma recorrente para construção do conhecimento (PETERSON, 2004; SMITH; HOERSCH; GORDON, 1995) com propósito de desenvolver novas habilidades e atitudes (BUFREM; SAKAKIMA, 2003). A literatura também explora o papel do docente como facilitador e não replicador do conhecimento (DOCHY et al., 2003; HUNG; JONASSEN; LIU, 2008). Nesta pesquisa verificou-se a aplicação da teoria em face destas vertentes além dos benefícios para os discentes. No entanto a literatura não apresenta como construir e aplicar o ABP.

Em vista do exposto e, baseado na experiência da implementação do método nesta pesquisa, sugere-se a seguir as sete recomendações para implementação do ABP, conforme foi tratado na figura 1, a começar pelo primeiro ponto, por referir-se à definição do objetivo e das habilidades a serem alcançadas, caso contrário o ABP será superficial com espaço para diversos gaps. Após a definição, recomenda-se a aplicação da taxonomia, tendo em vista que apenas seguir procedimentos e recomendações genéricas não garantem o desenvolvimento do método, o que justifica a existência de diversas formas para implementar o ABP (HUNG, 2011 apud BARROW, 1996) tais como o ABP puro, ABP híbrido, instrução ancorada, aprendizagem baseada em projetos, aprendizagem baseada em casos e instrução com atividades de resolução de problemas. No caso apresentado, o docente utilizou o ABP baseado em projetos, pois os alunos tiverem orientações parciais e a problemática foi construída de forma semiestruturada e em consonância com o docente, além de apresentarem conhecimento prévio e básico da temática a ser solucionada.

A terceira etapa consiste na construção e a definição de uma problemática que pode partir tanto do professor como do aluno que, ao participar do processo, sente-se mais engajado e motivado a solucionar o problema, tal qual ocorreu em nosso exemplo. Dependendo do contexto e, em razão da imaturidade profissional, caso o aluno apresente problema, poderá acarretar mais barreiras para o docente conduzir a implantação da metodologia. Ao compartilhar e construir em conjunto, os alunos conseguem se posicionar

Perspectivas em Gestão \& Conhecimento, João Pessoa, v. 8, n. 2, p. 179-193, maio/ago. 2018. 
face ao problema sugerido e o professor contribui no refinamento alinhando o processo ao objetivo, evitando dispersão ou rotas metodológicas mais arriscadas, uma vez que há prazos e conteúdo a ser cumprido dentro do cronograma estabelecido.

$\mathrm{Na}$ quarta etapa, penúltima, o professor se deparou com os diferentes níveis de grau de instrução e, mesmo diante de um quadro discente matriculado no semestre vigente e partindo do pressuposto que possuem as mesmas informações técnicas do curso, o nível de aprendizagem é divergente, uma vez que cada um apresenta habilidades e competências distintas cabendo ao professor amenizar este ponto. O ABP permite essa flexibilidade pedagógica em detrimento de uma proposta voltada a atender determinadas necessidades específicas, muito embora o professor precise acompanhar a evolução dos alunos em atividades realizadas em grupos, a fim de reduzir o grau de conflito devido as diferenças na busca da melhor solução do problema proposto.

Figura 1. Recomendações para implementação do ABP
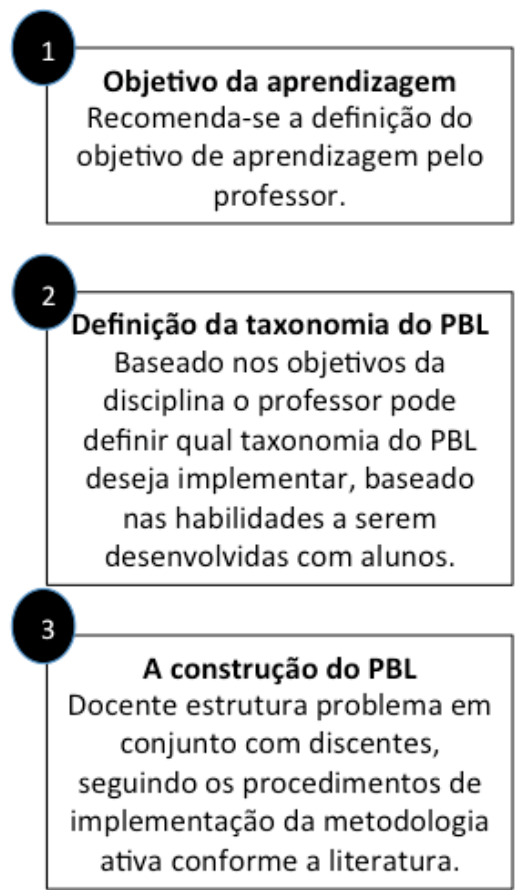

Fonte: Elaborado pelo autor
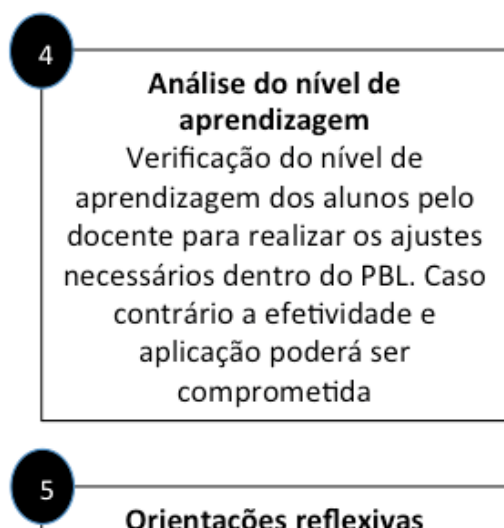

Orientações reflexivas

Docente deve assumir papel de facilitador e não de crítico, julgador. Recomenda-se que sua postura seja mais reflexiva e construa questionamentos nas afirmações e propostas do aluno e não replicador do conhecimento.

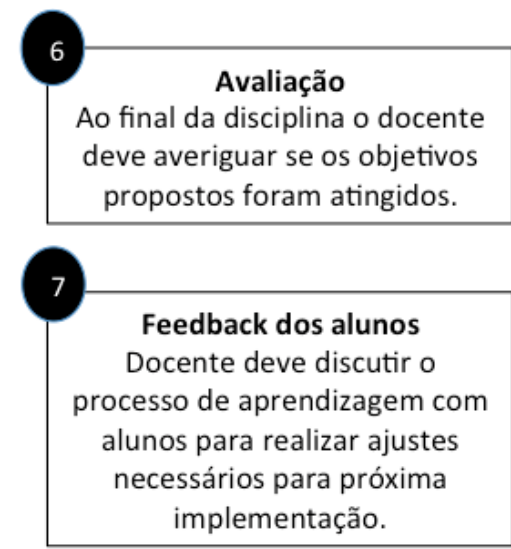
implementação.

A quinta e última etapa refere-se à postura do docente ao tornar-se um facilitador e construtor do conhecimento em parceria com discente ao gerar questionamentos, porém sem julgamentos, ou então posicionar aluno como coadjuvante. Finalizada a aplicação do método, o docente pode conferir as etapas de forma conjunta, analisando se objetivos propostos inicialmente foram atingidos e quais as percepções dos discentes referente a aplicação do ABP em sala de aula.

\section{CONSIDERAÇÕES FINAIS}

Os debates sobre a eficácia da aprendizagem baseada em problemas (ABP) apresentaram uma concepção teórica com foco nos resultados de aprendizagem, todavia ainda é considerada ausente no universo educacional superior (HUNG, 2011). Em vista disso, este artigo apresentou recomendações focadas na implementação do ABP alinhado à

Perspectivas em Gestão \& Conhecimento, João Pessoa, v. 8, n. 2, p. 179-193, maio/ago. 2018. 
experiência vivida curso de Administração como estratégia de metodologia ativa, o que evidenciou resultados positivos na formação do discente, partindo da concepção de projeto executado pelas IES. No entanto, ao realizar a preparação do método, o professor percebeu que não é suficiente apenas elaborar uma problemática, mas deve seguir procedimentos e atentar-se às taxonomias do método. Vê-se, no $A B P$, uma técnica centrada no aluno que, ao se organizarem em grupo, colaboram na construção de seus próprios conhecimentos de forma integrada e baseada em saberes pré-existentes, o que viabilizou a identificação de problemas, coleta e análise de dados relevantes, formulação e teste de hipóteses, sempre avaliando criticamente (SMITH; HOERSCH; GORDON, 1995).

Nesse estudo, viu-se a necessidade de recomendações para implementação do ABP, o que enseja novas pesquisas para verificar quais as formas desse método são mais eficazes e como devem ser mensuradas e implementadas. Por este motivo, cabe ao professor pesquisar e aprofundar quais as melhores formas de conduzir e potencializar o processo de aprendizagem. Nesta linha, este caso de ensino, além do seu objetivo de apresentar algumas recomendações para implementação do $A B P$, permite e recomenda novas pesquisas para verificar quais as formas do ABP são mais eficazes e como devem ser mensuradas e implementas em IES pelos docentes. Desta forma, pode-se evitar aplicações práticas equivocadas das metodologias de ensino e evitando a sua banalização no processo de aprendizagem. Cabe ao professor pesquisar e aprofundar quais as melhores formas de conduzir e implementar as metodologias ativas para potencializar o processo de aprendizagem.

Por fim, a pesquisa apresenta suas limitações devido a amostra selecionada. Desta forma, pode-se recomendar que a pesquisa possa ser ampliada para amostras maiores e para diferentes cursos e talvez sejam evidenciadas novas dificuldades entre docentes e discentes no processo de implementação do $A B P$ em face do ensino tradicional, resistências e demanda de tempo no processo de elaboração do conteúdo em foco em problemas. Este cenário pode contribuir para novas estratégias de implementação do ABP e abrir novas discussões sobre a temática em pesquisas futuras.

\section{REFERÊNCIAS}

ALBANESE, M.; MITCHELL, S. Problem-based learning: A review of literature on its outcomes and implementation issuesAcademic Medicine, 1993.

ASSEN, J. H. E. et al. Explaining discrepancies between teacher beliefs and teacher interventions in a problem-based learning environment: A mixed methods study. Teaching and Teacher Education, v. 60, p. 12-23, 2016.

AZER, S. A. Problem-based learning in the fifth, sixth, and seventh grades: Assessment of students' perceptions. Teaching and Teacher Education, v. 25, n. 8, p. 1033-1042, 2009.

BAXTER, G. P.; SHAVELSON, R. J. Science performance assessments: benchmarks and surrogates. International Journal of Educational Research, v. 21, n. 3, p. 279-298, 1994.

BAZANINI, R.; SANTANA, N. C. Gestão e Conhecimento nas Ciências Sociais Aplicadas.: uma experiência didática relacionada ao ensino-aprendizagem da disciplina Filosofia da Administração. Perspectivas em Gestão \& Conhecimento, v. 5, n. 1, p. 64-84, 2015. 
BARROWS, H. S. Problem-based learning in medicine and beyond: a brief overview. In: WILKERSON, L.; GIJSELAERS, W. H. (eds.). Bringing problem-based learning to higher education: theory and practice. San Francisco: Jossey-Bass, 1996, p. 3-12.

BOLHUIS, S.; VOETEN, M. J. . Toward self-directed learning in secondary schools: what do teachers do? Teaching and Teacher Education, v. 17, n. 7, p. 837-855, 2001.

BOUD, D.; FELETTI, G. The challenge of problem-based learning. Londres: Kogan Page, 1999.

BUFREM, L. S.; SAKAKIMA, A. M. O ensino, a pesquisa e a aprendizagem baseada em problemas. Transinformação, v. 15, n. 3, p. 351-361, 2003.

CARRIGER, M. S. Problem-based learning and management development - Empirical and theoretical considerations. The International Journal of Management Education, v. 13, n. 3, p. 249-259, 2015.

CHNG, E.; YEW, E. H. J.; SCHMIDT, H. G. Effects of tutor-related behaviours on the process of problem-based learning. Advances in Health Sciences Education, v. 16, n. 4, p. 491-503, 2011.

DENZIN, N.; LINCOLN, Y. S. Handbook of qualitative research. In: SAGE (Ed.). p. 1-17.

DOCHY, F. et al. Effects of problem-based learning: A meta-analysis. Learning and Instruction, v. 13, n. 5, p. $533-568,2003$.

DUNLAP, J. C. Problem-Based Learning and Self-Efficacy: How a Capstone Course Prepares Students for a Profession. Educational Technology Research and Development, v. 53, n. 1, p. 65-85, 2005.

ELCIN, M. et al. Developing and evaluating professionalism. Medical teacher, v. 28, n. 1, p. 3639, 2006.

FLICK, U. Desenho da pesquisa qualitativa. 3. ed. Porto Alegre: Artmed, 2009.

GIOIA, D. A.; CORLEY, K. G.; HAMILTON, A. L. Seeking Qualitative Rigor in Inductive Research: Notes on the Gioia Methodology. Organizational Research Methods, v. 16, n. 1, p. 15-31, 24 jul. 2012.

GOH, K. What Good Teachers Do to Promote Effective Student Learning in a Problem-Based Learning Environment. Australian Journal of Educational \& Developmental Psychology, v. 14, n. 65, p. 159-166, 2014.

GORMAN, G.; HANLON, D.; KING, W. Some research perspectives on entrepreneurship education, enterprise education and education for small business management:Aten-year literature review. Small Business Journal, v. 15, n. 3, p. 56-77, 1997.

GUBA, E. G.; LINCOLN, Y. S. Competing Paradigms in Qualitative Research. Handbook of qualitative research, p. 105-117, 1994.

HADGRAFT, R.; HOLECEK, D. (1995) Viewpoint: towards total quality using problem-based learning. International Journal of Engineering Education, 1995, v. 11, n. 1, p. 8-13.

Perspectivas em Gestão \& Conhecimento, João Pessoa, v. 8, n. 2, p. 179-193, maio/ago. 2018. 
HMELO-SILVER, C. E.; BARROWS, H. S. Goals and Strategies of a Problem-based Learning Facilitator. Interdisciplinary Journal of Problem-Based Learning, v. 1, n. 1, p. 5-22, 2006.

HUNG, W. Theory to reality: A few issues in implementing problem-based learning. Educational Technology Research and Development, v. 59, n. 4, p. 529-552, 2011.

HUNG, W.; JONASSEN, D. H.; LIU, R. Problem-Based Learning. Handbook of research on educational communications and technology, p. 485-506, 2008.

JONASSEN, D. H. Instructional Design Models for Well-Structured and III-Structured ProblemSolving Learning Outcomes. Educational Technology Research and Development, v. 45, n. 1, p. 65-90, 1997.

JONES, N. L. et al. Problem-based learning for professionalism and scientific integrity training of biomedicai graduate students. Process evaluation. v. 36, n. 10, p. 620-626, 2010.

MASETTO, M. T. PBL na educação? In: ENDIPE, 12., 2004, Curitiba. Anais. Curitiba: Editora Universitária Champagnat, v. 2, p. 181-189.

PETERSON, T. O. So You're Thinking of Trying Problem Based Learning?: Three Critical Success Factors for Implementation. Journal of Management Education, v. 28, n. 5, p. 630-647, 2004.

POWELL, P. From classical to project-led education. In: POUZADA, A. S. (ed.). Project based learning: project-led education and group learning. Guimarães: Editora da Universidade do Minho, 2000, p. 11-40.

ROTGANS, J. I.; SCHMIDT, H. G. The role of teachers in facilitating situational interest in an active-learning classroom. Teaching and Teacher Education, v. 27, n. 1, p. 37-42, 2011.

SAVERY, J. R. Overview of Problem-based Learning: Definitions and Distinctions. Interdisciplinary Journal of Problem-based Learning, v. 1, n. 1, p. 9-20, 2006.

SCHMIDT, H. G. et al. Constructivist, Problem-Based Learning Does Work: A Meta-Analysis of Curricular Comparisons Involving a Single Medical School. Educational Psychologist, v. 44, n. 4, p. 227-249, 2009.

SMITH, D. L.; HOERSCH, A. L.; GORDON, P. R. Problem-Based Learning in the Undergraduate Geology Classroom. v. 43, p. 149-152, 1995.

TAN, C. P.; VAN DER MOLEN, H. T.; SCHMIDT, H. G. To what extent does problem-based learning contribute to students' professional identity development? Teaching and Teacher Education, v. 54, p. 54-64, 2016.

TARDIF, M. Saberes docentes e formação profissional. Petrópolis: Editora Vozes, 2002.

TAYLOR, I.; BURGESS, H. Responding to 'non-traditional' students: an enquiry and action approach. In: BOUD, D.; FELETTI, G. (eds.). The challenge of problem-based learning. Londres: Kogan Page, 1999, p. 103-116.

Perspectivas em Gestão \& Conhecimento, João Pessoa, v. 8, n. 2, p. 179-193, maio/ago. 2018. 
WOODS, D. R. Problem-based learning: how to get the most out of PBL. Disponivel em: <http://www.biology.iupui.edu/Biology?HTML Docs/biocourses/k345/PBL Web Page>.

Acesso em: 06 dez. 2016.

WIJNIA, L. et al. University teacher judgments in problem-based learning: Their accuracy and reasoning. Teaching and Teacher Education, v. 59, p. 203-212, 2016.

YEW, E. H. J.; GOH, K. Problem-Based Learning: An Overview of its Process and Impact on Learning. Health Professions Education, v. 2, n. 2, p. 1-5, 2016.

Artigo recebido em 10/07/2017 e aceito para publicação em 30/05/2018 